Facilitating self-regulation in higher education through self-report

\title{
Introduction
}

For quite some time learning has been increasingly understood to be consistent with a constructivist perspective, and more recently with a social constructivist perspective (Resnick, 1989), in which knowledge is not passively received from the world, from others, or from authoritative sources. Rather, all knowledge is created as individuals (and groups) adapt to and make sense of their experiential worlds. Accordingly, people learn by being involved, by being active in the learning process and often working in collaboration with others; learners are active constructors and organisers of their own learning through comparing extant knowledge with new ideas and resolving the tensions created by conflicting or contradictory information; and finally, learners' construction of knowledge is a self-regulating process. Instead of learning being viewed as a passive, externally directed process in which the learner is a knowledge consumer, it is now more usually thought of as an active and self-directed process in which learners build or construct internal representations that are personal interpretations of their learning experiences.

This view of learning as self-regulated knowledge construction instead of consuming preselected, pre-pared and pre-packaged knowledge has implications for pedagogical practices. Instead of viewing teaching only in terms of the traditional knowledge-transmitting paradigm (Brophy, 2002; Collins et al, 1989), it is perhaps better conceptualised as being grounded in knowledge of how learning occurs (Gagné, 1970; Glaser, 1991). Furthermore, in developing teaching practices that focus on how students learn, it is argued that the learners' percepts of, and behaviour in, the learning situation are of prime importance (Brophy, 2002; Shuell, 1986, 1996; Vermunt \& Verloop, 1999).

The prominence attributed to the learner's own mediation of the learning experience(s) foregrounds the importance of understanding learners' perceptions of their sense of autonomy in a formal learning environment (Wosnitza \& Nenniger, 2001). For Wosnitza \& Nenniger (2001) 
Facilitating self-regulation in higher education through self-report

this sense of autonomy is predicated on the constructs of learning need (in which the learner's desire to ameliorate a perceived deficit in declarative or procedural knowledge initiates the learning process) and motivational control (in which the learner's desire to progress particular learning is understood to depend on his/her strategic behaviour to direct the learning process). In other words, unless the learner actually wants to learn (from which one can infer that the learner has some goal in mind) and unless the learner engages in activities to progress the learning (assuming that the learner can regulate learning at least to some extent), learning is not likely to take place (Pintrich \& DeGroot, 1990; Garcia \& Pintrich, 1994). This implies that we cannot explain learning as directly emanating from the learner's ability, personality or demographic characteristics, nor can we explain learning as directly emanating from the cultural or contextual features of the environment. Rather, learning would appear to be a function of the learner's personally initiated strategies to improve both achievement and environment, rendering selfregulation to be fundamental in efficient and powerful learning (Boekaerts, 1997). Furthermore, all learners attempt to regulate their own academic learning (Zimmerman, 1998) but some are more skilful while others remain naïve. This suggests that it is clearly of pedagogic importance that self-regulation is understood in an elaborated way in order that congruent teaching practices can be developed (Vermunt \& Verloop, 1999).

\section{Academic Self-Regulation}

Self-regulation is a cyclical process of cognitive engagement in which purposive behaviour is planned, adapted and evaluated (Butler \& Winne, 1995; Zimmerman, 2000, 2001). Typically the whole process comprises three or four phases (depending on how any one conceptual model demarcates the different forms of cognitive engagement), which are generally ordered in time but which are not hierarchical thereby allowing the possibility of phases operating simultaneously and dynamically (Ertmer \& Newby, 1996; Pintrich, 2004). The first phase is one of forethought or planning in which learners set clear goals, select and sequence a series of strategies and/or 
Facilitating self-regulation in higher education through self-report

procedures to realise the goals and identify potential barriers to the successful realisation of their goals, on the basis of their extant knowledge (procedural, declarative, strategic and conditional). A second phase is one of monitoring which involves learners being aware of what they are doing; understanding where what they are doing fits in to the already determined sequence of steps and anticipating what ought to be done next. The third phase is one of learners implementing and adapting their strategies to maintain control over themselves or the task. Because both monitoring and regulation are being carried out throughout the execution of the plan, these phases can be difficult to distinguish empirically (Pintrich, et al, 2000) and may quite properly be collapsed into one (Ertmer \& Newby, 1996). The final phase is one of reaction to, and reflection on, the outcome of the execution of the plan in which learners may compare their current progress with their goals, make attributions for their progress and evaluate aspects of the task environment to judge both the appropriateness of their goals and their own strategic behaviour. Of the various phases, the planning and setting of goals is critical because it is this which establishes the direction of subsequent learning. As such it is of superordinate importance since there can be no self-regulation without goal direction (Winne, 1997). In each and all of these processes, there is the potential for learners to perform skilfully or naively. The differences catalogued turn on the distinction that skilful self-regulators view academic learning as something they do for themselves while naïve self-regulators see themselves as victims of their learning experiences. Studies reviewed by Butler \& Winne. (1995) suggest that naïve self-regulation is very common but that it can become more skilful through interventions which require skilled self-regulatory behaviour for task completion.

However, while self-regulation is documented as a necessary condition for efficient learning, there is a lack of clarity in the literature (Pintrich et al, 2000; Zeidner et al, 2000) as to the conceptual distinction between self-regulation and metacognition. In positing self-regulation to be a complex web of conceptual dimensions (Boekaerts, 1999; Boekaerts \& Minnaert, 1999; 
Facilitating self-regulation in higher education through self-report

Pintrich et al, 2000; Zimmerman, 1994), most models of self-regulation would accord a role to metacognition (Zimmerman \& Schunk, 2001), although specific models vary as to the centrality of this construct. A further potential for confusion is in the lack of distinction between selfregulated learning as a cognitive competency and self-regulation as the behavioural performance of a skill (Zimmerman \& Risemberg, 1997). While the psychological literature makes clear that self-regulation is essentially a cognitive competency, for which there may or may not be behavioural tactics (Pintrich et al, 2000; Winne et al, 2002), the very fuzziness of the construct may render the pedagogic significance of self-regulation to be incidental rather than fundamental to those of us wanting to improve the learning environment (Boekaerts, \& Minnaert, 1999) but who do not have the appropriate psychological knowledge. It is therefore important in the context of higher education generally that tutors, who may not themselves research student motivation and learning, understand self-regulation in a way that they can readily harness in their own teaching contexts. There are good reasons for believing that learners' conceptions of their own attempts to acquire knowledge and to apply such knowledge to their own intellectual development are important sources of pedagogic information for tutors, and therefore worthy of investigation. One reason is that skilful self-regulation is associated with greater forethought to preparing for learning, with more effective effort in carrying out the learning task, with more comprehensive reflection on the volitional control exercised in the realisation of the learning goal and with improved academic achievement (Zimmerman, 1998). Another reason is that selfregulation is the mechanism through which transfer of learning occurs (Martinez-Pons, 2001) within the paradigm of social cognition (Fiske \& Taylor, 1991). So by enabling students to make explicit their own self-regulation they are then in a better position to improve their strategies where these are understood to be important, given that students can complete undergraduate courses in higher education and yet have no more than a basic, quantitative conception of learning (Dahlgren, 1997; Eraut, 1994). To this end, the purpose of the study reported here was to pilot a modified version of the Five-Component Scale of Self Regulation (Martinez-Pons, 2000) as a 
Facilitating self-regulation in higher education through self-report

pedagogic tool with higher education students in their development of self-regulatory behaviour. Specifically the study was testing whether a set of instructional prompts, derived from the modified version of the Five-Component Scale of Self Regulation (and used to augment an instructional module designed to introduce, and have students apply, concepts of motivation and thinking) could influence students' goal-setting, strategy implementation and monitoring of their learning.

\section{Accessing and measuring self-regulation}

The essentially complex, and potentially ambigous, quality of self-regulation makes clear that it is not amenable to either simple or direct measures. For Winne \& Perry (2000) one criterion in determining the measure depends on whether self-regulation is predominantly an aptitude or an event. If self-regulation is largely an event, appropriate measures would include think aloud protocols, error detection tasks and trace methodologies (Winne \& Perry, 2000) since these measures focus on the thoughts and cognitive processes of individual learners when carrying out particular, and possibly uniqe, tasks. If, however, self-regulation is construed largely as an aptitude in which a general, or default, perspective is sought in relation to the typical responses of learners, then self-report questionnaires or structured interviews are appropriate measures (Winne \& Perry, 2000). The purpose of the study reported here was to explore self-regulation as an aptitude amenable to influence through a pedagogical tool for potential use with a range of tutors in a variety of situations. Furthermore, since the strength of the self-report questionnaire is in its facility to measure propensities to use different self-regulatory processes, rather than to measure behaviour in particular contexts (Pintrich et al, 2000; Winne \& Perry, 2000; Winne et al, 2002), the use of one such instrument was deemed to fulfill the pedagogic intentions of the study.

\section{Method}


Facilitating self-regulation in higher education through self-report

Design A cohort study was conducted in which university students experienced instruction that aligned module material and self-regulatory prompts. To test the efficacy of the intervention, the self-regulation measure was administered before and after module delivery.

Instrument A modified version of the Five-Component Scale of Self Regulation (MartinezPons, 2000) was used in favour of the popular Learning and Study Strategies Inventory (LASSI) (Weinstein et al, 1988) and the Motivated Strategies for Learning Questionnaire (MSLQ) (Pintrich et al, 1993), both of which might have been selected (Winne \& Perry, 2000). LASSI was rejected because of its focus on students' approaches to learning (SAL) than on self-regulated learning (SRL) (Biggs, 1993; Pintrich, 2004) and MSLQ was rejected because the hierarchical design of the instrument results in self-regulation being accorded a relatively small place. The Five-Component Scale of Self Regulation (Martinez-Pons, 2000) has as its exlusive focus the construct of self-regulation, and was seen to be consistent with the assumptions of social cognition. Further, it is a more recent instrument, which is beneficial (Richardson, 2004), and has been validated on both school pupils and students in higher education. The component scales of goal-setting, strategy implementation and monitoring were selected. Some surface and cosmetic changes to item wording and item order were made to present good face validity to a UK sample. For the 15 items in each scale of the questionnaire, participants were invited to indicate the frequency - never, sometimes, frequently, all the time - with which they engaged in each of the behaviours. The use of the questionnaire protocol presumed that the participants did possess some strategy knowledge, if not also some strategy skill (Zimmerman ,1999) and while neither of these hypotheses was tested in advance of questionnaire administration, directing the participants to make use of a peripheral context when making their responses is a both practised and practical way of administering the self-report questionnaire (Pintrich et al, 1993; Winne \& Perry, 2000). Nevertheless, a self-report questionnaire cannot probe the respondents' awareness of the processes they are using to regulate their learning, their ability to describe and report on their 
Facilitating self-regulation in higher education through self-report

metacognitive processing (even when selecting from available alternatives) nor their honesty in reporting (Tobias \& Everson, 2000).

Procedure for gathering data The investigator administered the questionnaire to all participants during class times. The questionnaire contained forty-five (45) items and thirty (30) minutes were allowed for its completion. In the administration of the questionnaire prior to the intervention, participants were given scripted verbal instruction as follows:

Here are some suggestions about what people do and don't do when they are learning. Consider how true, if at all, each statement is for you, in your BEd studies and put a tick in the box that best represents your views.

In the administration of the questionnaire after the intervention, participants were given scripted verbal instruction as follows:

Here are some suggestions about what people do and don't do when they are learning. Consider how true, if at all, each statement is for you now that you have completed the module on Understanding Yourself as a Learner and put a tick in the box that best represents your views.

Procedure for intervention The module aims were to introduce concepts of motivation and thinking and to have the students apply these concepts to their own learning. Module delivery was organised round engagement in solo and collaborative tasks and was consistent with a constructivist perspective (Hickey \& McCaslin, 2001; Tynjälä, 1999). The module comprised specified and additional reading, lectures (to the entire cohort) and discussion groups (of about 20 students) in which students were required to engage in a range of learning tasks to transform (through applying or concretising, memorising or rehearsing, critiquing, analysing, relating or structuring, selecting or summarising) ideas that they had read or heard about. These tasks were essentially the thinking activities that people use to learn (Vermunt \& Verloop, 1999). In all of the elements of the module students had available an aide-mémoire of self-regulatory prompts (listed in Table I) reminding them that at any point tutors or peers could ask for clarification as to 
the strategy or tactic that was guiding a particular task or part of a task. The rationale for providing prompts is that they may support students who are deficient in producing the relevant regulatory behaviours at appropriate points (Veenman et al, 2005).

Insert Figure I about here, please

Participants Seventy-five (75) students (59f. and 16 m.) of whom 50 were aged between 17 and 21 years and the remainder were mature (over 21 years) students comprised the sample. First year students from a Scottish University, studying for a Bachelor's degree in Primary Education (a professional qualification with a license to practice) were registered for a compulsory and accredited two-semester module entitled, Understanding Yourself as a Learner; the pedagogic intervention around which the measures were taken.

Analysis Strictly speaking, since the data gathered were ordinal measures they should have been analysed non-parametrically. However Cramer (1998) argues that at times ordinal measures can be subjected to parametric testing since what is being tested is whether there is any difference between measures, with there being no claims either for the interval or ratio of the measure. On the basis of Cramer's reasoning, therefore, parametric tests will be used.

\section{Results}

The results refer to the frequency on a scale from 1 to 4 (never, sometimes, frequently, all the time) with which constituent behaviours of goal-setting, strategy implementation and monitoring were deployed before and after a pedagogic intervention. If the exploration and promotion of goal-setting, strategy implementation and monitoring are to be fostered through a specific tool, the reliability of the instrument used is of prime importance. The study showed Cronbach's alphas before the intervention to be $\alpha=.88$ for goal setting, $\alpha=.90$ for strategy implementation, and $\alpha=.92$ for monitoring; while the values after the intervention were $\alpha=.88$ for goal setting, $\alpha$ 
Facilitating self-regulation in higher education through self-report

$=.79$ for strategy implementation and $\alpha=.92$ for monitoring. These coefficients are typically understood to constitute an acceptable level of internal reliability in most Social Science applications.

Comparison of pre-intervention and post-intervention mean subscales on paired sample t-tests all show significant difference: Goal Setting, $t(74)=-19.46, \mathrm{p}<0.001$; Strategy Implementation, $t$ (74) $=-19.81, \mathrm{p}<0.001$; Monitoring, $t(74)=-20.61, \mathrm{p}<0.001$. Even if a repeated measures design had not been appropriate, independent t-tests to compare the pre and post scores on each of the three scales (more conservative than the paired samples t-test) still yield significant difference with $\mathrm{p}<0.001$ for all three subscales: goal setting, $t(148)=-17.56, \mathrm{p}<0.001$; Strategy Implementation, $t(148)=-17.89, \mathrm{p}<0.001$; Monitoring, $t(148)=-18.97, \mathrm{p}<0.001$

Insert Table I about here, please.

These tests support the conclusion that the intervention influenced the three main elements of self-regulation. In other words, students reported significantly increased awareness of, and engagement with, sets of behaviours that are thought to constitute self-regulation. Clearly, it would have been desirable to have had these differences corroborated by the scores from a control group but the resource constraints of this exploratory study meant that participants who would be comparable in all other respects could not be included. A further limitation of this study is that although there is a difference reported in engagement in self-regulation, it is not fully clear how the intervention has contributed to this. For scientific purposes, it is clearly important to understand self-regulation in more detail but for pedagogic purposes it is sufficient to be persuaded that the differences evidenced in this study have a robustness that warrants continued examination of the intervention. The Discussion will attempt to unpack possible explanations for the intervention's effects. 
Facilitating self-regulation in higher education through self-report

\section{Discussion}

The purpose of the study reported here was to explore whether students' reported goal-setting, strategy implementation and monitoring might be influenced by specific pedagogic intervention. From the changes in scores on the three scales, it is possible to claim that students reported that they engaged in more self-regulation after the intervention than they did prior to it though the contributing effects of the module material and the self-regulatory prompts themselves cannot be teased apart at the moment. The reported increase in self-regulation can be understood through a number of related lenses.

One is the lens of expertise. Experts are able to think more effectively about problems since they possess an organised and integrated body of conceptual and procedural knowledge that can be both readily accessed and used with superior metacognitive skill (Glaser \& Chi, 1988). Ericsson (2002) argues that expertise is a function of deliberate practice, practice that is mediated by experience in domain related activities, engagement in activities that will promote domain expertise and the cognitive mediation of the individual. For example, experts will familiarise themselves with the specific and peculiar features of the contexts in which they are to operate. In so doing they will retrieve pertinent prior knowledge for potential use and plan how this might be best deployed. They will then anticipate likely consequences from following one or more planned course of action and in the course of this may well construct alternative/better courses of action. These features of expertise were reflected in characteristics of the intervention. Strategy instruction was integrated into the domain-specific content of the module in recognition of the evidence that points to the interplay between self-regulation and other-regulation; a form of teaching known as process-oriented instruction (Vermunt, 1995). This meant that engagement in learning tasks was explicitly prefaced with the requirement to analyse the assignment, identify task demands and articulate performance criteria. Next, the determination of task strategy had to be justified in terms of the performance criteria and when these did not match well, further 
Facilitating self-regulation in higher education through self-report

planning and goal-setting was required. A further requirement was that students articulated the stages of the strategy in their own words and finally, the outcomes of the strategy implementation had to be modified/fine tuned. What was possibly happening was that the intervention was emphasising the phases of self-regulation which are themselves the very phases that experts deploy in their cognitive mediation of tasks.

A second possible lens through which to understand the results is that of pedagogy. Pedagogical content knowledge is knowledge of how to structure and represent particular academic content for teaching; knowledge of the common conceptions, misconceptions and difficulties that students may have when learning particular content; and knowledge of the specific strategies that can be used to address students' needs in particular classroom circumstances (Shulman, 1987). Such knowledge guides tutors' actions and reasoning in highly contextualised classroom settings. In other words pedagogical content knowledge is conditionalised on a set of circumstances: it cannot be reduced to sets of facts or isolated propositions but reflects the contexts of applicability. Without pedagogical content knowledge, tutors are unable to help students to learn when, where and why to use content knowledge. Tutors' pedagogical interventions can be characterised as strong tutor control, weak tutor control or shared control (Vermunt \& Verloop, 1999). In strong tutor control the tutor is perceived to be taking a major role in the cognitive, affective and regulatory activities that are needed to secure high-quality learning, whereas in loose tutor control the tutor assumes that learners will of their own volition engage in appropriate cognitive, affective and regulatory activities. Too much tutor control can mean that the tutor is clarifying the subject matter, offering examples, suggesting arguments for or against a point of view and so on such that the students' need to think (and therefore to learn) is minimised. Because too much tutor control replaces/compensates for low metacognitive awareness, students who are not skilled in the phases of self-regulation may view the tutor's metacognition as essential for the development of their own skills and knowledge, leaving such students over dependent on tutors 
Facilitating self-regulation in higher education through self-report

(Boekaerts, 1999). Too little tutor control can mean that students have complete and unconditional choice as to what cognitive processes to engage without any criteria to judge their progress, a possibly unsatisfactory state of affairs for students who want some teacher regulation of their learning processes. An intermediate position is shared control in which students carry out the various cognitive, motivational and regulatory activities but do so through the stimulation of tutors who perhaps ask detailed questions, have students present arguments, require students to analyse the cause of their problems or otherwise assign tasks that give choice and responsibility to the students (Vermunt \& Verloop, 1999). It was this shared control which was inherent in the delivery of the module where, through the selection of reading and lecture content, relevant material was brought into the arena by tutors but was cognitively processed by the students (Vermunt \& Verloop, 1999) who controlled the processing through their regulatory choices with such control being scaffolded (with all that this implies for support) by tutors. So what the intervention possibly allowed the tutors to do was to foreground, through the cyclical phases of the prompts, that self-regulatory strategies are useful and meaningful in the construction of new domain-specific knowledge.

A third possible lens is that of personal epistemology in which students' beliefs about the nature of knowledge about their own ability to learn (Pintrich, 2003) influence the ways in which they approach, engage in and evaluate their learning, with some types of beliefs constraining the use of deeper processing (Schommer, 1993). According to Boekaerts $(1997,1999)$ and Pintrich $(2000)$, when students adopt a mastery goal orientation (in which they strive to increase their competence through understanding or mastering something new) rather than a performance goal orientation (where individuals strive to gain favourable, and avoid negative, judgements of their competence) they are more likely to persist in the cognitive and metacognitive activities that will improve their learning such that they review goals that they have already set, modify their strategic engagement to take account of evaluations of self-set goals and engage in adaptive help seeking. This means 
Facilitating self-regulation in higher education through self-report

that not only might students not know about how and when to deploy particular regulatory behaviours, they may further have beliefs that limit their choice of behaviours; which implies that intervention to improve self-regulation should include targeting the beliefs that students may have of learning. However students have multiple and often conflicting goals for their learning (Oettingen et al, 2000) and within the largely formal learning environment of higher education, students' and tutors' intentions for learning may not be congruent (Boekaerts \& Minnaert, 1999). The possibly tight prescription of the curriculum and emphasis on formally assessed learning outcomes which require students to remain on task regardless of their interest in the topic, may result in perceptions of little student latitude to set their own subsidiary goals. The increased reporting in self-regulation may have been a function of the intervention's repeated emphasis on setting specific, proximal goals, through which students learned to make clear both the standards and the amount of effort required for progressive success (Bandura, 1997; Boekaerts et al 2000; Locke \& Latham, 1990), thereby enabling them to elaborate their representations of selfregulation (Boekaerts, 1997). It is when students appreciate the meaning and worth of the learning goal, using it to steer and direct their behaviour that they can integrate their regulation of learning with the development of their domain-specific knowledge (Boekaerts, \& Minnaert, 1999). So what the intervention possibly allowed was an emphasis on self-referential standards to heighten the sense of efficacy that derives from the successful attainment of prior goals, thereby stimulating the setting of even more challenging goals (Bandura, 1997).

\section{Conclusion}

The purpose of the study was to to pilot a modified version of the Five-Component Scale of Self Regulation (Martinez-Pons, 2000) as a vehicle for activating and engaging learners' existing prior knowledge of goal setting, strategy implementation and monitoring both before and during learning tasks. The results point to a particular pedagogical intervention resulting in increased reporting in the different phases of self-regulation. While we would not wish to over interpret 
Facilitating self-regulation in higher education through self-report

data from a single study with a limited sample and many potential biases, what the intervention appeared to be doing was enhancing students' understanding of the components of self-regulation, helping students to understand how the components influence performance and prompting the students to act in accordance with the phases of self-regulation thereby promoting its routinisation. Furthermore the intervention did not engender a helpless response but made clear that self-regulated learning is neither easy nor automatic and may be demanding in terms of time and effort (Pintrich, 2003). In students whose achievement is less than optimal because of their lack of detailed criteria against which to observe, evaluate and transform their own learning behaviour, the use of a structured self-recording instrument that focuses on and informs students as to the nature and effectiveness of their current learning would appear to be useful. As well as being the necessary first step of enabling higher education students to make explicit their own self-regulatory behaviours (Zimmerman, 1999), the modified version of the Five-Component Scale of Self Regulation (Martinez-Pons, 2000) is a possible mechanism through which to practise and reflect on such tactics and strategies as they employ, since it draws attention to the cognitive and metacognitive processing that is fundamental to high-quality learning.

In discussing the significance of these changes, it is recognised that while the scales used were targeting academic learning (and as such may be assumed to emphasise cerebral activity), the scales do not exclude the possibility that motivation as well as cognition was being regulated (Boekaerts, 1997, 1999: Järvelä \& Niemivirta, 1999; Winne, 1995), nor that behaviour and context were also being regulated since it is learners' perceptions of their involvement in both behaviour and context (rather than particular behaviours or contexts per se) that are the focus of self-regulatory activity (Pintrich, 2004). Thus not only does self-regulation comprise various components (cognition, motivation, affect, behaviour and context) but these components interact to provide individuals with the feedback that they use to evaluate whatever strategies were selected to achieve particular goals. The increase in reported self-regulation confirms that self- 
Facilitating self-regulation in higher education through self-report

regulation does not exist in isolation, but must be aligned with the curriculum and with instruction if it is to support students' learning, because students cannot regulate their learning without taking account of the environmental conditions that obtain. In other words self-regulation interacts reciprocally with the environment such that self-regulation is not merely a process of adjusting to changing environmental circumstances, but rather it is the purposeful engagement which takes cognisance of changing environmental circumstances but which nevertheless is directed towards particular goals.

\section{References}

Bandura, A. (1997). Self-efficacy: the exercise of control. New York: Freeman.

Biggs, J. (1993). What do inventories of students' learning processes really measure? British Journal of Educational Psychology, 63, 3-19.

Boekaerts, M. (1997) Self-regulated learning: a new concept embraced by researchers, policy makers, educators, teachers and students. Learning and Instruction, 7(2) 161- 86.

Boekaerts, M. (1999) Self-regulated learning: where we are today. International Journal of Educational Research, 31(6) 445-57.

Boekaerts, M. \& Minnaert, A. (1999). Self-regulation with respect to informal learning. International Journal of Educational Research: 31(6) 533-44.

Boekaerts, M., Pintrich, P. \& Zeidner, M. (Eds.). (2000). Handbook of Self-regulation. San Diego: Academic Press.

Brophy, J. (2002). Social Constructivist Teaching: Affordances and Constraints. Oxford: Elsevier Science Ltd. 
Facilitating self-regulation in higher education through self-report

Butler, D. \& Winne, P. (1995). Feedback and self-regulated learning: a theoretical synthesis. Review of Educational Research: 65(3), 245-81.

Collins, A. Brown, J. \& Newman, S. (1989). Cognitive apprenticeship: teaching the crafts of reading, writing and mathematics in L Resnick (Ed.), Knowing, Learning and Instruction (pp.453-494). Hillsdale, New Jersey: Lawrence Erlbaum Associates.

Cramer, D. (1998) Fundamental Statistics for Social Research. London: Routledge.

Dahlgren, L. (1997) Learning conceptions and outcomes. In F. Marton, D. Hounsell \& N.

Entwistle (Eds) The Experience of Learning (pp. 23-38). Edinburgh, Scotland: Scottish Academic Press.

Eraut, M. (1994) Developing Professional Knowledge and Competence. London: The Falmer Press.

Ericsson, K. (2002) Attaining excellence through deliberate practice. In: C. Desforges \& R. Fox (Eds.) Teaching and Learning: The Essential Readings (pp.4-37). London: Blackwell

Ertmer, P. \& Newby, T. (1996). The expert learner: strategic, self-regulated, and reflective. Instructional Science: 24, 1-24.

Fiske, S. \& Taylor, S. (1991). Social Cognition. New York: McGraw-Hill.

Gagné, R. (1970) The Conditions of Learning. New York: Holt, Rinehart \& Winston.

Garcia, T. \& Pintrich, P. (1994). Regulating motivation and cognition in the classroom: the role of self-schemas and self-regulatory strategies. In: D. Schunk \& B. Zimmerman (Eds.), SelfRegulation of Learning and Performance (pp.127-53). Hillsdale New Jersey: Lawrence Erlbaum Associates. 
Facilitating self-regulation in higher education through self-report

Glaser, R. (1991) The maturing of the relationship between the science of learning and cognition and educational practice. Learning and Instruction: 1, 129-44.

Glaser, R. \& Chi, M. (1988) Overview, In: M. Chi, R. Glaser \& M. Farr (Eds.) The Nature of Expertise (pp.xv-xxvii) Hillsdale, NJ: Erlbaum.

Hickey, D. \& McCaslin, M. (2001) A comparative, sociocultural analysis of context and motivation. In S. Volet \& S. Järvelä (Eds.) Motivation in Learning Contexts (pp. 33-55). London: Pergamon.

Järvelä, S. \& Niemivirta, M. (1999) The changes in learning theory and the topicality of the recent research on motivation. Research Dialogue in Learning and Instruction 1, 57-65

Locke, E. \& Latham, G. (1990). A Theory of Goal Setting and Task Performance. Englewood Cliffs: NJ: Prentice-Hall.

Martinez-Pons, M (2000, June). Effective transfer as a self-regulatory process: implications for adult education. Paper presented at the Royaumont Symposium on Self-Learning, Paris.

Martinez-Pons, M (2001). The Psychology of Teaching and Learning. London: Continuum.

Oettingen, G., Hönig, G. \& Gollwitzer, P. (2000) Effective self-regulation of goal attainment. International Journal of Educational Research, 33 (7-8), 705-32.

Pintrich, P. \& DeGroot, E. (1990). Motivational and self-regulated learning components of classroom academic performance. Journal of Educational Psychology: 82(1), 33-40.

Pintrich, P., Smith, D., Garcia, T. \& McKeachie, W. (1993) Reliability and predictive validity of the motivated strategies for learning questionnaire (MSLQ) Educational and Psychological Measurement, 53, 801-13. 
Facilitating self-regulation in higher education through self-report

Pintrich, P, (2000) The role of goal orientation in self-regulated learning. In: M. Boekaerts, P. Pintrich \& M. Zeidner (Eds.). Handbook of Self-regulation (pp.451-502). San Diego: Academic Press.

Pintrich, P, Wolters, C. \& Baxter, G. (2000) Assessing metacognition and self-regulated learning. In G. Schraw \& J. Impara (Eds.) Issues in the Measurement of Metacognition (pp. 44-97) Lincoln: Buros Institute of Mental Measurement.

Pintrich, P. (2003) Multiple goals and multiple pathways in the development of motivation and self-regulated learning. In: L. Smith, C. Rogers \& P. Tomlinson (Eds.) Development and Motivation, BJEP Monograph Series 2 (2), 137-53. Leicester: The British Psychological Society

Pintrich, P. (2004) A conceptual framework for assessing motivation and self-regulated learning in college students. Educational Psychology Review, 16(4), 385-407.

Resnick, L. (1989) (Ed.) Knowing, Learning and Instruction. Hillsdale, NJ: Lawrence Erlbaum Associates.

Richardson, J. (2004) Methodological issues in questionnaire-based research on student learning in higher education. Educational Psychology Review, 16(4) 347-358.

Schommer, M (1993) Epistemological development and academic performance among secondary students. Journal of Educational Psychology, 85 (3) 406-11

Shuell, T. (1986) Cognitive conceptions of learning. Review of Educational Research, 56(4) 411 36.

Shuell, T. (1996) Teaching and learning in a classroom context. In D. Berliner \& R. Calfee (Eds.) Handbook of Educational Psychology (pp.726-64). London: Macmillan. 
Facilitating self-regulation in higher education through self-report

Shulman, L. (1987). Knowledge and teaching: foundations of the new reform, Harvard Educational Review, 57(1), 1-22.

Tobias, S. \& Everson, H. (2000) Assessing metacognitive knowledge monitoring. In G. Schraw \& J. Impara (Eds.) Issues in the Measurement of Metacognition (pp. 147-222) Lincoln: Buros Institute of Mental Measurement.

Tynjälä, P. (1999) Towards expert knowledge? A comparison between a constructivist and a traditional learning environment in the university. International Journal of Educational Research, $31(5) 357-442$

Veenman, M., Kok, R. \& Blőtte, A. (2005) The relation between intellectual and metacognitive skills in early adolescence. Instructional Science, 33, 193-211

Vermunt, J. (1995) Process-oriented instruction in learning and thinking skills. European Journal of Psychology of Education, 10(4), 325-49

Vermunt, J. \& Verloop N. (1999) Congruence and friction between learning and teaching. Learning and Instruction, 9, 257-80.

Weinstein, C., Zimmerman, S. \& Palmer, D. (1988) Assessing learning strategies: the design and development of the LASSI. In C. Weinstein (Ed) Learning and Study Strategies: Issues in Assessment, Instruction and Evaluation (pp.25-40). London: Academic Press.

Winne, P. (1995) Inherent details in self-regulated learning. Educational Psychologist, 30 (4), 173-187.

Winne, P. (1997) Experimenting to bootstrap self-regulated learning. Journal of Educational Psychology, 89 (3) 397-410 
Facilitating self-regulation in higher education through self-report

Winne, P., Jamieson-Noel, D. \& Muis, K. (2002) Methodological issues and advances in researching tactics, strategies and self-regulated learning. In P. Pintrich \& M. Maer (Eds.) Advances in Motivation and Achievement: Vol. 12 New Directions in Measures and Methods (pp.121-155). Amsterdam: Elsevier Press

Winne, P. \& Perry, N. (2000) Measuring self-regulated learning. In M. Boekaerts, P. Pintrich \& M. Zeidner (Eds.). Handbook of Self-regulation (pp.531-566). San Diego: Academic Press.

Wosnitza, M. \& Nenniger P. (2001) Perceived learning environments and the individual learning process. In S. Volet \& S. Järvelä (Eds.) Motivation in Learning Contexts (pp. 171-187). London: Pergamon.

Zeidner, M., Boekaerts, M \& Pintrich, P. (2000) Self-regulation: directions and challenges for future research. In M. Boekaerts, P. Pintrich \& M. Zeidner (Eds.). Handbook of Self-regulation (pp.749-768). San Diego: Academic Press.

Zimmerman, B (1994). Dimensions of academic self-regulation: a conceptual framework for education. In: D. Schunk \& B. Zimmerman (Eds.), Self-Regulation of Learning and Performance (pp.3-21). Hillsdale New Jersey: Lawrence Erlbaum Associates.

Zimmerman, B. (1998). Developing self-fulfilling cycles of academic regulation. In: D. Schunk \& B. Zimmerman (Eds.), Self-Regulated Learning (pp.1-19). London: The Guildford Press.

Zimmerman, B. (1999) Commentary: toward a cyclically interactive view of self-regulated learning. International Journal of Educational Research: 31(6) 545-51.

Zimmerman, B \& Risemberg, R. (1997) Caveats and recommendations about self-regulation of writing: a social cognitive rejoinder. Contemporary Educational Psychology, 22, 115-22. 
Facilitating self-regulation in higher education through self-report

Zimmerman, B. (2000) Attaining self-regulation. In M. Boekaerts, P. Pintrich, \& M. Zeidner (Eds.) Handbook of Self-regulation. (pp. 13-39) San Diego: Academic Press.

Zimmerman, B. (2001) Theories of self-regulated learning and academic achievement in B.

Zimmerman \& D.Schunk (Eds.) Self-Regulated Learning and Academic Achievement (pp. 1-37).

Mahwah New Jersey: Lawrence Erlbaum Associates

Zimmerman, B. \& Schunk, D. (Eds.) (2001), Self-Regulated Learning and Academic

Achievement. Mahwah New Jersey: Lawrence Erlbaum Associates

Acknowledgements: The authors are grateful to Jim McCall, Emeritus Professor of Education, University of Strathclyde, for his helpful comments on an earlier draft of the manuscript. 
Facilitating self-regulation in higher education through self-report

\section{Figure I Self-Regulatory Prompts}

1. Have I set an achievable goal for this task?

2. Have I set a manageable but definite deadline (date, time) for reaching my goal?

3. Have I checked (maybe with others) that my goal is clear/realistic/manageable?

4. Is this goal presenting me with a challenge or going beyond what I have already achieved

5. Am I keeping track of my goals

6. Am I asking others (tutors/students/friends/family) to help me when I get stuck?

7. Am I motivating myself to work when I am tired/find the material difficult or boring/find other distractions?

8. Am I taking notes during class/using the library to get information?

9. Am I organising my academic work so that I remember information presented in class or in textbooks?

10. Am I persisting with my work when I am tired/find the material difficult or boring/find other distractions?

11. Am I checking that my method of working is helping me towards my goal(s)?

12. Am I being selective/flexible in the use of alternative working methods?

13. How do my working methods and performance compare with those used previously and/ used by others?

14. Am I testing myself to see how well I'm doing?

15. Am I searching for and correcting errors I may have made? 
Facilitating self-regulation in higher education through self-report

Table 1 Mean Ratings for GOAL SETTING, STRATEGY IMPLEMENTATION and MONITORING

$\underline{\text { Subscales }}$

\begin{tabular}{|c|c|c|c|}
\hline Pre-intervention ratings & Mean & Std. Deviation & N \\
\hline Goal Setting mean score & 2.1369 & .38732 & 75 \\
\hline Strategy mean score & 2.1938 & .38907 & 75 \\
\hline Monitoring mean score & 2.0356 & .40601 & 75 \\
\hline
\end{tabular}

\begin{tabular}{|c|c|c|c|}
\hline Post-intervention ratings & Mean & Std. Deviation & N \\
\hline Goal Setting mean score & 3.1689 & .33013 & 75 \\
\hline Strategy mean score & 3.1840 & .28003 & 75 \\
\hline Monitoring mean score & 3.2560 & .38141 & 75 \\
\hline
\end{tabular}

